\title{
De la culpa al seguro. \\ La Ley de Accidentes de Trabajo, \\ Argentina (1915-1955).
}

\section{Karina Inés Ramacciotti}

Resumen: Este artículo apunta a rastrear las ideas y políticas efectivamente puestas en práctica en torno a la Ley de Accidentes de Trabajo entre 1915 a 1955 en la Argentina. El derrotero de la sanción e implementación de esta ley permite revisar los cambios y/o las continuidades que se introdujeron en las discusiones técnicas en torno a los cuidados de la salud de los trabajadores en relación con su labor. En este artículo analizamos -a partir de fuentes institucionales, revistas profesionales y jurisprudencia-las relaciones entre las agencias estatales y los profesionales.

Palabras clave: Accidentes de trabajo - Agencias estatales - Salud laboral - Argentina.

Abstract: This article traces the ideas and the polices effectively implemented from the Work Accident Law between 1915 and 1955 in Argentine. The sanction and implementation of this law allow us to consider the changes and continuities that were introduced in worker healthcare's technical discussions. Thus, this article shows the relations among state agencies and professionals through an array of institutional sources, professional magazines and jurisprudence.

Key-words: workplace accidents - state agencies - labour health - Argentina.

\section{INTRODUCCIÓN}

Este artículo apunta a rastrear el derrotero que siguieron las ideas y las políticas efectivamente implementadas en relación con la Ley de Accidentes de Trabajo entre 1915 y 1955 en la Argentina. En este trayecto revisaremos cuáles fueron los cambios y también las continuidades introducidas en las discusiones técnicas en torno a los accidentes que podían

\footnotetext{
* Este trabajo forma parte de del proyecto UBACYT "Trabajo y salud en la Argentina: saberes académicos y políticos (1915-1955)", Facultad de Medicina, Universidad de Buenos Aires, y del PICT (2248) "Historia de las instituciones laborales en Argentina: del Departamento Nacional del Trabajo al Ministerio de Trabajo". ANPCyT, Argentina. Agradezco las valiosas sugerencias de los integrantes de ambos grupos de trabajo y las de los evaluadores anónimos de la revista. Correo electrónico: karinaramacciotti@gmail.com.

** La autora es Investigadora Adjunta del Instituto Interdisciplinario de Género/CONICET y Profesora de Historia de la Medicina de la Facultad de Medicina de la Universidad de Buenos Aires.
} 
sufrir los trabajadores en sus ámbitos de labor o las enfermedades que se podrían producir motivadas por el ambiente laboral. ${ }^{1}$

Buscamos dialogar con aquellos autores que estudiaron las relaciones entre el Estado y sus cuerpos técnicos y administrativos. ${ }^{2}$ Así pues, los informes realizados por médicos y juristas que formaban parte del Departamento Nacional de Higiene y del Departamento Nacional del Trabajo, ambos integrantes del Ministerio del Interior hasta la llegada del peronismo, constituyen una fuente insoslayable para este trabajo. En estos meticulosos registros oficiales se describía el estado social y sanitario de los trabajadores, y por medio de ellos se buscaba crear las condiciones para que el Estado interviniera en las relaciones laborales en pos de mitigar las consecuencias sociales de la pobreza y el conflicto social. En forma paralela, estas voces técnicas intentaban, con estas sugerencias y descripciones detalladas, mantener, reforzar y legitimar sus inserciones profesionales en las reparticiones estatales. ${ }^{3}$ Asimismo, las relaciones de estas reparticiones -el Departamento Nacional de Higiene y el Departamento Nacional del Trabajo- dan cuenta de cómo, en el largo plazo, la agencia laboral ocupó espacios que en su origen eran atribuidos al organismo sanitario. Revisar estas complementaciones, superposiciones y tensiones entre las instituciones constituye un esfuerzo para complejizar el estudio de la formación histórica del Estado argentino. ${ }^{4}$

Cabe señalar que desde fines del siglo XIX, en la Argentina, los sindicatos, los partidos políticos y el movimiento anarquista venían denunciando, entre otras cuestiones, las

\footnotetext{
${ }^{1}$ El interés por la higiene y seguridad en el trabajo tenía como referentes tanto la legislación e ideas previas como diagnósticos internacionales. Desde fines de siglo XIX y principios de siglo XX la radical Elvira Rawson, segunda médica en Argentina, y los socialistas Juan B. Justo, Augusto Bunge, José Ingenieros, Ángel Giménez y Enrique Dickman habían enunciado la importancia de resguardar los ambientes de trabajo. Véase RECALDE, Héctor. La salud de los trabajadores en Buenos Aires. 1870-1910 a través de las fuentes médicas, Buenos Aires, Grupo Editor Universitario, 1997; y ARMUS, Diego. La ciudad impura. Salud, tuberculosis y cultura en Buenos Aires, 1870-1950, Buenos Aires, Edhasa, 2007.

${ }^{2}$ NEIBURG, Federico y PLOTKIN, Mariano. Intelectuales y expertos, Buenos Aires, Paidós, 2004. Véase una síntesis de las diferentes formas de pensar el Estado en el trabajo de BOHOSLAVSKY, Ernesto y SOPRANO, Germán. "Una evaluación y propuestas para el estudio del Estado en Argentina”. En BOHOSLAVSKY, Ernesto y SOPRANO, Germán (editores). Un estado con rostro humano. Funcionarios e instituciones estatales en Argentina (desde 1880 a la actualidad), Buenos Aires, Prometeo/ Universidad Nacional de General Sarmiento, 2010.

${ }^{3}$ Véase un estudio del Departamento Nacional de Higiene en GONZÁLEZ LEANDRI, Ricardo. "Breve historia del Departamento Nacional de Higiene. Estado, gobernabilidad y autonomía médica en la segunda mitad del silo XIX". Para el estudio del Departamento Nacional del Trabajo SOPRANO, Germán. "Haciendo inspección. Un análisis del diseño y aplicación de la inspección laboral por los funcionarios del Departamento Nacional del Trabajo (1907-19149". Ambos textos en BOHOSLAVSKY, Ernesto y SOPRANO, Germán (editores). Un estado con rostro humano. Funcionarios e instituciones estatales en Argentina (desde 1880 a la actualidad), Buenos Aires, Prometeo/Universidad Nacional de General Sarmiento, 2010. Véase también LOBATO, Mirta. "Historia de las instituciones laborales en Argentina: una asignatura pendiente". Revista de Trabajo, Año 3, № 4, noviembre de 2007, y SURIANO, Juan. "La política laboral durante el primer gobierno de Hipólito Yrigoyen: entre continuidades y rupturas, el rol del Departamento Nacional de Trabajo" (mimeo).

${ }^{4}$ Una referencia obligada para estudiar las características e instancias de penetración del Estado argentino entre 1862-1888 véase en OSZLAK, Oscar. La formación del Estado argentino, Editorial Universidad de Belgrano, Buenos Aires, 1982.
} 
pésimas condiciones de higiene y de labor en las fábricas. Con diferentes matices discursivos y de protesta interpretaban que las enfermedades que contraían y los accidentes que sufrían los trabajadores en su puesto laboral constituían uno de los aspectos visibles de una relación basada en la explotación y que sólo apuntaba a aumentar los márgenes de la ganancia capitalista. Son estas denuncias y los dispositivos de protesta utilizados los que actuaron como una caja de resonancia para que los organismos estatales decidieran intervenir, reconocer ciertos derechos y organizar un tímido andamiaje institucional. No obstante, este trabajo se centrará en la manera en que las miradas de los profesionales interpelaron al Estado y fueron diseñando normas, instituciones, controles y sanciones para lograr la progresiva implementación de las leyes. ${ }^{5}$

Así pues, pretendemos realizar un aporte al estudio de la política social y revisar cómo los informes técnicos y las demandas judiciales se constituyen en un corpus documental interesante para rastrear los conflictos entre la patronal y los obreros, y cómo se interpelaron las instituciones de gobierno para impulsar cambios en la legislación y en los armazones institucionales. Es decir, los cambios en las políticas sociales pueden ser incitados por varios factores en constante diálogo o tensión. Como demostró Eduardo Zimmerman, un sector reformista dentro de la élite, proveniente del campo liberal, socialista o del catolicismo social, propuso reformas para mitigar las consecuencias del conflicto social y mantener el statu quo. Desde diferentes campos disciplinares, abogados y médicos impulsaban la transformación de la normativa jurídica que regulaba el mundo laboral a fin de ofrecerles garantías a los trabajadores en tanto sujetos de derechos de una república moderna, y de asegurar modos de resolución más rápidos y efectivos para los cada vez más agudos enfrentamientos entre la patronal y sus trabajadores. ${ }^{6}$ Como ha sido estudiado por Aldo Isuani y, más recientemente, por Juan Suriano, los efectos de los conflictos obreros impulsaron iniciativas estatales destinadas a regular las relaciones laborales. Estos referentes obligados para el estudio de las políticas sociales deben ser estudiados conjuntamente. Aquí proponemos acercarnos a esa doble vertiente a través del estudio de las demandas judiciales y la implementación de la legislación. Ello permite revisar no sólo la sanción de una ley sino cómo ésta se reforma (o no) en el proceso de su puesta en práctica. ${ }^{7}$

\footnotetext{
${ }^{5}$ Para ampliar sobre el estudio del movimiento obrero en la Argentina y sus reivindicaciones véase BARRANCOS, Dora. La escena iluminada. Ciencias para trabajadores. 1890-1930, Buenos Aires, Plus Ultra, 1996. LOBATO, Mirta. La vida en las fábricas, Buenos Aires, Prometeo/Entrepasados, 2000. SURIANO, Juan. Anarquistas: cultura y política libertaria en Buenos Aires. 1890-1910. Buenos Aires, Manantial, 2001; y DEL CAMPO, Hugo, Sindicalismo y Peronismo. Los comienzos de un vínculo perdurable, Buenos Aires, Siglo XXI, 2005. PALERMO; Silvana. "Ciencia, reformismo político y los derechos del trabajador-ciudadano: la regulación estatal del trabajo ferroviario según Bialet Massé”, Buenos Aires, Entrepasados. Revista de Historia, №. 26, principios de 2004, pp. 31-52.

${ }^{6}$ ZIMMERMAN Eduardo. Los liberales reformistas (1890-1916), Buenos Aires, Sudamericana, 1995 y PALERMO; Silvana. "Ciencia, reformismo político y los derechos del trabajador-ciudadano: la regulación estatal del trabajo ferroviario según Bialet Massé", Buenos Aires, Entrepasados. Revista de Historia, №. 26, principios de 2004, pp. 31-52.

${ }^{7}$ SURIANO, Juan. "Introducción: Una aproximación a la definición de la cuestión social en Argentina". En SURIANO, Juan (comp.). La cuestión social en la Argentina (1870-1943), Buenos Aires, La Colmena, 2000.
} 
En función de estos intereses, este artículo tendrá dos apartados. En el primero revisaremos las causas por las cuales en 1915 se crearon las condiciones sociales para sancionar la Ley de Accidentes de Trabajo. En función de esto, analizaremos cómo las demandas judiciales y las voces profesionales impulsaron la incorporación de modificaciones a la ley imperante. En segundo lugar, exploraremos cómo las discusiones por la sanción del seguro social durante el peronismo, que finalmente nunca se llevó a la práctica, introdujeron cambios institucionales y modificaciones en torno al manejo de los recursos, pero no impulsaron modificaciones a la ley sancionada en 1915.

\section{EL RECONOCIMIENTO JURÍDICO DE QUE EL TRABAJO ENFERMA}

Hasta 1915, el principio jurídico que regía las relaciones entre patrones y obreros en lo respectivo al resarcimiento por daños relacionados con el trabajo era la denominada "culpa patronal". La aplicación de este corpus legal tendía a reparar algunos pocos accidentes. El obrero debía cargar con la tramitación y el costo que le suponía culpabilizar al patrón por los daños o lesiones sufridas; asimismo, la asistencia médica y farmacéutica en los casos de accidentes corría por cuenta de la víctima. ${ }^{8}$ Dicho de otra forma, si se producía un accidente, el patrón era responsable únicamente si el trabajador podía demostrar la responsabilidad de aquel, y los gastos que suponía esta demostración corrían por su cuenta. Los obreros pocas veces conseguían una contraprestación asistencial o en dinero por el daño sufrido. Los recurrentes accidentes dentro y fuera de los ámbitos de trabajo y las denuncias registradas especialmente en la prensa y en las manifestaciones obreras pusieron en el tapete la necesidad de reformar la legislación vigente. Asimismo, los cambios tecnológicos en los espacios fabriles -realizados sin reparar en la necesaria capacitación de los obrerosincrementaron las posibilidades de sufrir lesiones. ${ }^{9}$

En 1915, se dictó la primera Ley de Accidentes y Enfermedades del Trabajo $\left(\mathrm{N}^{\circ}\right.$ 9.688), reglamentada por el Poder Ejecutivo el 14 de enero de 1916. El antecedente legislativo más inmediato de esta ley es la № 9.085, homologada en 1913. Esta última había sido impulsada a partir de un caso particular: la llamada "Catástrofe del Riachuelo": en los talleres del Ministerio de Obras Públicas, que estaban ubicados en las márgenes del

También ISUANI, Aldo. Los orígenes conflictivos de la seguridad social en la Argentina, Buenos Aires, Centro Editor de América Latina, 1985.

${ }^{8}$ Un análisis del debate previo en torno a la necesidad de implementar la legislación laboral véase en HIDART, Victoria. Trabajadores en riesgo. Una sociología histórica de la biopolítica de la población en Argentina (18901915), Buenos Aires, Prometeo, 2008.

${ }^{9}$ LIENUR, Jorge y SILVESTRE, Graciela. El umbral de la Metrópolis, Transformaciones técnicas y cultura en la modernización de Buenos Aires, 1870-1930, Buenos Aires, Sudamericana, 1993. 
Riachuelo, ${ }^{10}$ se había producido una explosión, y por medio de esta ley se indemnizó a las víctimas o a sus familias. Dicha normativa, además, facultó al Poder Legislativo para proceder de igual forma en casos análogos. ${ }^{11}$

La ley sancionada en 1915 se basó en la idea del riesgo profesional. ${ }^{12}$ Según sus enunciados, poco importaba que el patrón fuera o no culpable, lo que interesaba era que existiera un riesgo y, en virtud de él, el empleador debía remediar la desgracia si ésta llegara a ocurrir. Es decir, el obrero ya no tendría que demostrar la culpa del patrón, sino que era éste quien debía probar la negligencia grave o la culpa del obrero si sus intenciones pasaban por no resarcirlo. Con la Ley $\mathrm{N}^{\circ} 9.688$ se sustituyó la culpa del patrón, como fundamento del derecho, por la reparación en caso de accidente o enfermedad producida por el hecho de trabajar. Si antes la prueba de la culpa incumbía a la víctima, ahora la prueba era la relación de causa y efecto entre el ejercicio del trabajo y el accidente. Así pues, el armazón jurídico reconoció, por un lado, que el trabajo enfermaba y que era el patrón quien debía resarcir el daño; por otro lado, también estipuló que era el Estado, por medio de sus agencias, el que tenía la obligación de tutelar las relaciones laborales.

La formulación de esta nueva prescripción jurídica, a través de la cual se trataron de mitigar algunos aspectos de las relaciones laborales frente a la ausencia de un código laboral, fue introducida para resguardar la fuerza de trabajo indispensable para la reproducción del sistema productivo. Esto deber ser inserto dentro de un contexto histórico en el cual los flujos inmigratorios extranjeros declinaban a causa de la Primera Guerra Mundial y por los efectos de la crisis financiera (1913-1917). En forma paralela, ya existían dudas en torno al supuesto factor de regeneración social que traería el trabajador extranjero a la sociedad argentina. La conflictividad social y la expansión de las ideas socialistas y anarquistas generaban un cono de sombras en torno al supuesto papel regenerador de la mano de obra extranjera. ${ }^{13}$ Darle prioridad, entonces, a la preservación del "capital humano local" fue percibido como una vía para aumentar la productividad e intentar alejar a los grupos considerados "díscolos" que atentaban contra el idealizado orden nacional.

La incorporación de la idea jurídica de riesgo profesional a la legislación argentina -a tono con las ideas imperantes respecto de reformas sociales y laborales- amplió el campo de los accidentes indemnizables y posibilitó la reparación de un variado arco de dolencias y enfermedades profesionales con un resarcimiento económico. Los parámetros económicos serían proporcionales al salario, determinados por una tarifa y liquidables por medio de un procedimiento administrativo. A mayor salario, más alto sería el monto a percibir. No

\footnotetext{
${ }^{10}$ El Riachuelo es un curso de agua de $64 \mathrm{~km}$, que nace en la provincia de Buenos Aires y desemboca en el Río de la Plata, y que constituye el límite Sur de la Ciudad Autónoma de Buenos Aires. En sus zonas aledañas funcionaron talleres, fábricas y curtiembres, y en sus márgenes se encuentra uno de los barrios vinculados con la inmigración decimonónica: La Boca.

${ }^{11}$ RIVA, Oscar Alfredo. "Diversas teorías sobre la reparación de accidentes". Boletín Informativo de Leyes de Trabajo, marzo de 1942, p. 32.

12 RIVA, Oscar Alfredo, "Diversas teorías sobre la reparación de accidentes". Boletín Informativo de Leyes de Trabajo, marzo de 1942, p. 33.
}

${ }^{13}$ BIERNAT, Carolina. ¿Buenos o útiles? La política inmigratoria del peronismo, Buenos Aires, Biblos, 2007. 
obstante, existía un tope para reclamar la indemnización, y era para quienes ganaban más de tres mil pesos anuales. De esta manera se pretendía proteger a los obreros más necesitados y también los intereses patronales. Esta decisión se justificaba en que frente a salarios mayores no habría empresa ni industria que pudiera sostenerse; con lo cual queda claro que los intereses garantizados eran los de no modificar la tasa de ganancia. Si bien se reconocía la necesidad de resguardar las condiciones de la mano de obra, este interés no debería lesionar la reproducción del sistema capitalista. ${ }^{14} \mathrm{El}$ límite salarial era arbitrario, puesto que no consideraba qué porcentaje implicaba ese monto en la economía familiar, ni tampoco los aumentos de precios de la canasta familiar que la misma agencia laboral registraba en sus informes. Así, se continuaban reproduciendo las desigualdades sociales y se mantenían amplias diferencias entre las franjas salariales.

Además, se impuso la asistencia médica y farmacéutica de la persona lesionada, y los gastos de sepelio y entierro en caso de muerte. ${ }^{15}$ La asistencia médica y las responsabilidades patronales respecto de ella eran claras. El patrón debería hacerse cargo de la recuperación, rehabilitación y cura de los lesionados. No obstante, desde 1916 hasta 1921, los patrones evitaban los gastos de la asistencia médica recurriendo a los servicios sociales que prestaban de manera gratuita los hospitales. Una ordenanza municipal suspendió esta medida: los hospitales continuaron brindando el servicio a los lesionados, pero luego debían pasar los honorarios profesionales a la empresa.

Si bien las ideas de accidente de trabajo o de enfermedad profesional no surgen de la Ley $\mathrm{N}^{\circ}$ 9.688, su Decreto Reglamentario sí avanzó en tal sentido. Así pues, se entendieron como accidentes de trabajo las alteraciones orgánicas o funcionales provocadas por un hecho súbito o violento e inesperado ocurrido durante del ejercicio de las tareas. En el artículo 2 de dicho decreto se definió por accidente de trabajo a

todo hecho que, en la ejecución del trabajo o en ocasión y por consecuencia del mismo, produzca lesiones corporales, mediatas o inmediatas, aparentes o no aparentes, superficiales o profundas. Se considera accidente del trabajo los hechos constituidos por caso fortuito o por fuerza mayor inherente al trabajo que produzcan las mismas lesiones. ${ }^{16}$

Esta definición cambiaba el registro de la reparación en tanto en ella se reconoció que la acción de trabajar implicaba riesgos para una persona, por un lado y, por otro, que era el empleador quien tenía la obligación de ampararla.

\footnotetext{
${ }^{14}$ En varios casos, las compañías aseguradoras tendían a tratar de demostrar que las víctimas ganaban más de tres mil pesos anuales para evitar indemnizarlas. El argumento era que al sueldo debían agregarse las propinas u otros rubros no declarados.

${ }^{15}$ RIVA, Oscar Alfredo. "Diversas teorías sobre la reparación de accidentes". Boletín Informativo de Leyes de Trabajo, marzo de 1942, p. 42.

${ }^{16}$ Decreto Reglamentario de la Ley № 9.688, extraído de AMILLANO, Antonio (recopilador). Legis/ación Nacional del Trabajo, Junta Central de la Acción Católica Argentina, Buenos Aires, 1939, p. 323.
} 
Las enfermedades profesionales fueron entendidas como aquellas dolencias originadas en la actividad desarrollada por el artesano, técnico, obrero u operario. En palabras del médico y diputado radical Leopoldo Bard, "las enfermedades profesionales son aquellas afecciones que atacan a ciertos obreros, como consecuencia necesaria del ejercicio de una profesión". ${ }^{17}$ Ciertas toxinas, olores, materiales con los que interactuaban diariamente y por un período prolongado de tiempo podrían afectar de manera negativa el organismo de los obreros, e incapacitarlos -momentánea o permanentemente- para continuar realizando la labor La propuesta de Bard era modificar las condiciones dentro del ambiente en que se producían. Como consecuencia, tanto en la ley como en diferentes tipos de publicaciones se incluyeron recomendaciones para mejorar el ambiente de trabajo; por ejemplo, hacer las modificaciones necesarias para conseguir una mayor ventilación e iluminación, o reparar los pisos para evitar accidentes, etc. Se consideraba que si se conseguía una mayor protección y capacitación para las personas en relación con sus actividades laborales, los accidentes de trabajo tenderían a disminuir.

Hacia los años treinta y cuarenta, se impulsó el uso de carteles preventivos, y con ello se apuntó a la responsabilidad individual de los trabajadores en función de evitar los accidentes. Para no pagar las indemnizaciones, fue habitual entonces que se apelara a su imprudencia.

La ley $\mathrm{N}^{\circ} 9.688$ declaró un variado arco de enfermedades profesionales, entendiendo como tales sólo a aquellas cuya causa se debía exclusivamente al trabajo de la víctima en la profesión que desempeñaba. Reconoció así a la neumoconiosis, tabacosis pulmonar, antracosis, siderosis, saturnismo, hidrargirismo, cuprismo, arsenicismo, oftalmía amoniacal, sulfocarbonismo, hidrocarbunismo, fosforismo, infección carbunclosa, dermatosis, anquilostomiasis, brucelosis. La Ley $\mathrm{N}^{\mathrm{o}} 11.544$ sobre Jornada de Trabajo, sancionada el 12 de septiembre de 1929, ordenó en su artículo segundo que se declarase insalubre toda actividad cuyo aire estuviera viciado o en el que se presentaran emanaciones de gases o polvos tóxicos. La confirmación de estas condiciones de trabajo determinaría la jornada de seis horas en lugar de ocho.

Estas modificaciones a la legislación fueron producto tanto de los reclamos obreros como de las demandas judiciales, los detallados informes emanados del Departamento Nacional del Trabajo y el Departamento Nacional de Higiene y de las sugerencias de diversos profesionales (médicos, abogados e ingenieros). A partir de 1916, se estableció la obligatoriedad de denunciar y registrar los accidentes de trabajo ante el Departamento Nacional del Trabajo; el Departamento Nacional de Higiene, por su parte, constataba el grado de incapacidad sufrido por el empleado. Hasta mediados de 1926, el trámite vinculado a la denuncia de accidentes de trabajo era competencia de la División de Inspección y Vigilancia del Departamento Nacional de Trabajo. Luego, las denuncias quedaron bajo la égida de la División de Estadística. El cambio se fundamentó en el hecho de que los inspectores, según la norma, debían vigilar que los establecimientos industriales cumplieran las leyes obreras. Las

${ }^{17}$ BARD, Leopoldo. Enfermedades Profesionales, Casa Editora y Librería Guido Buffarini, Buenos Aires, 1925, p. 15. 
quejas respecto de que sus tareas se estaban volviendo cada vez más administrativas, en referencia al llenando formularios, y menos vinculadas a la inspección, motivaron algunos cambios en la organización departamental. Esta modificación en el organigrama posibilitó que se sistematizaran cuantitativamente la cantidad de accidentados, los trámites iniciados, los casos mortales y las incapacidades parciales o totales. Estos relevamientos eran publicados mensualmente en las Crónicas del Departamento Nacional de Trabajo. ${ }^{18}$

Entre 1916 y 1927, las razones a las que solía apelar la patronal para no pagar los resarcimientos económicos eran, por ejemplo, las acusaciones a algunos empleados de ingerir excesivas cantidades de alcohol, la transgresión de los reglamentos laborales, el abandono del lugar de trabajo, el incumplimiento de los carteles preventivos y la negación de la existencia de alguna lesión previa al momento de su ingreso. En efecto, los patrones solían aducir que los empleados obviaban dar aviso de enfermedades preexistentes al momento de ocupar sus cargos, y que por lo tanto no les cabía responsabilidad alguna al respecto; situación muy difícil de comprobar si se tiene en cuenta que no existían los chequeos previos del personal contratado, ni la tecnología ni los conocimientos médicos permitían verificar que tales argumentos sólo constituían artilugios legales para no pagar una indemnización. ${ }^{19}$ A partir de 1928, algunos de ellos fueron desatendidos por la noción de "imprudencia profesional". Alejandro Unsain, presidente del Departamento Nacional del Trabajo, retomando conceptos de las legislaciones laborales italiana y francesa, apeló a este concepto, definido por el descuido que sobreviene al trabajador luego de sostener una misma actividad durante varias horas al día, que podría provocar que ciertas cuestiones peligrosas se convirtieran en parte de la cotidianeidad y que las constantes situaciones de peligro se naturalizaran. La perspectiva de Unsain indica que la correcta atención que un trabajador pone en sus tareas y en la prevención de accidentes durante los primeros días de trabajo se diluye con el correr del tiempo, las preocupaciones desaparecen y los descuidos se derivan de la rutina propia de la labor. Muchas de las acciones que sobrevenían en accidentes -anteriormente atribuidas al personal fabrilquedaron, a partir de esta perspectiva, bajo la responsabilidad patronal. Es decir, los trabajadores podrían violar los reglamentos o las costumbres del trabajo; sin embargo, el patrón no pudo ya establecer esto como un elemento que lo eximiera de responsabilidad. Si un obrero era imprudente en el armado de un andamio, por ejemplo, no podía ser considerado una culpa grave, pues para ello hubiera sido menester que constara que habían faltado indicaciones precisas de parte del patrón o del constructor. Así pues, la imprudencia se consideró como parte de un riesgo profesional, ya que el patrón tenía la obligación de revisar previamente los tirantes y la solidez de los materiales. $^{20}$

Como se puede apreciar, luego de diez años de haberse implementado, la legislación laboral sufrió diversos cambios, ya fuera de corte administrativo o conceptual; transformaciones que dan cuenta de las maneras en que las prácticas y los saberes profesionales se fueron entrelazando para producir modificaciones en las políticas laborales y

\footnotetext{
18 "Decreto disponiendo que la tramitación de los accidentes de trabajo estará a cargo de la División de estadística del Departamento Nacional del Trabajo". Crónica Mensual del Departamento Nacional del Trabajo, Año IX, № 103, 1926, pp. 1816-1817.

${ }^{19}$ MORDEGLIA, Miguel y FRANCONE, Mario. Tecnopatías, El Ateneo, Buenos Aires, 1950, pp. 14-15.

${ }^{20}$ Crónica Mensual del DNT, febrero de 1928, Año XI, N¹20, p. 2312.
} 
para limitar el impacto negativo de los accidentes y/o enfermedades en los trabajadores y sus familias. A partir de 1936, la Ley sufrió otra modificación sustancial: se incluyeron en ella los trastornos patológicos provocados por el efecto del radio y demás sustancias radiactivas, y los epiteliomas primitivos de la piel originados por la manipulación o el empleo de alquitrán, brea, betún, parafina, aceites minerales y los derivados de estos últimos. También se establecieron decretos reglamentarios por medio de los cuales se intentó completar el criterio de aplicación, y fueron incorporados el calambre profesional de los telegrafistas y la enfermedad de Weil. En la provincia de Buenos Aires se admitieron el anilismo, la enfermedad de los "Caissons", el efisema pulmonar, el lumbago y la tuberculosis. A partir de esta reforma, esta última quedó incorporada a la lista de lesiones profesionales (si se demostraba la relación entre ambiente laboral y el inicio de la enfermedad). Cabe señalar que la tuberculosis, enfermedad de alta incidencia entre la población obrera, era uno de los trastornos no contemplados por la legislación de 1915 ni por su Decreto Reglamentario. Las razones de esta ausencia radican en la utilización del argumento legal anteriormente enunciado. Como era muy difícil de determinar si era una enfermedad preexistente al ingreso laboral, era habitual que los trabajadores cuyo estado iba empeorando debieran pasar por períodos prolongados sin trabajar o que debieran, directamente, dejar de trabajar, con lo cual quedaban sin ninguna cobertura económica o asistencial. Con esta modificación se intentó resolver ese problema sólo, como señalamos, para los casos en que se demostrara la relación entre lugar de trabajo y enfermedad. ${ }^{21}$

Hacia 1940, la Ley 12.631 incorporó a la legislación los principios aceptados en la Confederación General de la Organización Internacional del Trabajo de la Liga de las Naciones. Dos fueron los aspectos destacados: la inclusión de las actividades avícolas, forestales, ganaderas y pesqueras, y la de los accidentes de los trabajadores antes o después de su jornada laboral. Con respecto al primero, si bien hacia 1915 el 50\% de la población obrera estaba abocada a las actividades rurales, éstas no estaban resguardadas. El argumento era que la agricultura no era una actividad peligrosa y que las prestaciones farmacéuticas y médicas no eran sencillas de conseguir en la campaña. ${ }^{22}$ Esa omisión invisibilizaba las lesiones de los trabajadores del campo que, por supuesto, también estaban expuestos a riesgos laborales. Así, los traumatismos generales, las radiaciones por electricidad atmosférica, las mordeduras de serpientes y artrópodos ponzoñosos quedaban fuera del amparo y sujetos al criterio de los jueces, que en alguna sentencia generaban juridisprudencia y antecedentes para cubrir a dichos trabajadores. ${ }^{23}$ En esta misma línea, la hidatidosis fue considerada en las pólizas de accidentes de trabajo como enfermedad profesional o rural. Dado que la enfermedad hidatídica era un peligro público, el Estado debía proteger a quienes la padecieran, ya fuera de forma temporal o permanente. Sin

\footnotetext{
${ }^{21}$ ARMUS, Diego. La ciudad impura. Salud, tuberculosis y cultura en Buenos Aires, 1870-1950, Buenos Aires, Edhasa, 2007, p. 188.

${ }^{22}$ RIVA, Oscar Alfredo. "Diversas teorías sobre la reparación de accidentes". Boletín Informativo de Leyes de Trabajo, marzo de 1942, p. 31.

${ }^{23}$ LICURZI, Ariosto, "Faltas de sentido médico en la legislación social argentina". La Prensa Médica Argentina, № 1, 1938, p. 31.
} 
embargo, surgían inconvenientes acerca de cómo determinar qué patrón era el responsable del pago la indemnización, pues la aparición de la enfermedad no era fácilmente detectable y la fecha de diagnóstico no coincidía con la de su inicio. ${ }^{24}$

En relación con la segunda inclusión -el reconocimiento los accidentes de los trabajadores antes o después de su jornada laboral- se abrió un amplio abanico de dudas y vacilaciones. La ley consagró el principio de comprobar la relación entre lugar y accidente: si éste se producía en el lugar de trabajo, se tendería a indemnizar. En la Cámara Civil 2음 tuvieron lugar fallos encontrados. El 24 de julio de 1923, había declarado que el riesgo en la calle era común a todos y, por lo tanto, no era indemnizable. Este fallo surgió a partir de la demanda entablada por la esposa de José Virgilio, un trabajador que, a principios de ese año, luego de haber sido despedido de su trabajo, sufrió un accidente, se golpeó y murió. El juez no dio lugar al pedido, ya que "no encontró la necesaria conexión entre el accidente y el trabajo" ${ }^{25}$ Diferente fue la suerte de Afonso Legaz, peón de una empresa de mudanzas, quien luego de hacer una descarga, descendió del carro, se cayó y quedó con una discapacidad en el pie. El patrón, para evitar el pago de la indemnización, adujo que Alfonso había bajado del carro para tomar una cerveza y no para darles de beber a los caballos, como el peón había argumentado. Como anticipamos, el alcoholismo era un argumento común utilizado por las empresas para evitar el pago de indemnizaciones. No obstante, este accidente quedó amparado por la legislación, dado que se había producido durante la jornada laboral. ${ }^{26}$

Ocho años después de los casos mencionados, se produjeron cambios en los fallos judiciales en torno a los accidentes de trabajo sucedidos fuera de la jornada laboral. El 22 de abril de 1931, un fallo de la Cámara Civil 1 o sostuvo que el accidente era indemnizable mientras que la persona se dirigiera a su trabajo. "Atropellado un obrero por un tranvía cuando se dirigía al trabajo, momentos antes de que iniciara las tareas, existe nexo de causalidad entre el trabajo y el accidente por lo que debe indemnizarle como un accidente de trabajo y no de tránsito". El Superior Tribunal de Entre Ríos procedió de manera similar el 13 de agosto de 1941 frente a la muerte de un obrero a causa de las heridas recibidas al ser embestido por un automóvil en circunstancias en que transitaba en bicicleta por la única calle de acceso a la fábrica y unos pocos minutos antes de la hora que debía iniciar sus tareas. ${ }^{27}$ Es probable que el aumento del tránsito en las zonas urbanas, a la luz de la modernización del parque automotor, incitara el reconocimiento de la peligrosidad que implicaba el camino que unía la casa con el ámbito laboral.

\footnotetext{
${ }^{24}$ Véase un análisis de esta enfermedad en VALOBRA, Adriana. "Un desafío a la justicia social peronista: la hidatidosis en la provincia de Buenos Aires, 1946-1952". História, Ciencia, Saude-MANGUINHOS, 2007, vol. 14, $\mathrm{N}^{\circ} 4$, p. 1357.

${ }^{25}$ Crónica Mensual del Departamento Nacional del Trabajo, febrero de 1926, año IX, № 98, p. 1737.

${ }^{26}$ Crónica Mensual del Departamento Nacional del Trabajo, febrero de 1926, año IX, № 98, p. 1737.

${ }^{27}$ RIVA, Oscar Alfredo. "Diversas teorías sobre la reparación de accidentes". Boletín Informativo de Leyes de Trabajo, marzo de 1942, p. 31.
} 
Estas incertidumbres quedaron saldadas con la reforma de 1940, momento en que se incluyeron los accidentes de tránsito en el cuerpo de la ley. A partir de entonces, fue obligación del patrón indemnizar al obrero que había sido víctima de un accidente en el camino entre su domicilio y el lugar de sus tareas, y desde éste a su hogar al culminar su horario de trabajo. Asimismo, los accidentes se indemnizarían si se producían por los peligros inherentes al acceso del establecimiento, como por ejemplo el cruce de vías férreas, ríos o puentes.

Las mayores dificultades para resolver los casos surgían cuando las cámaras no podían establecer la relación entre trabajo, accidente y enfermedades de trabajo; aunque había casos en que esta relación se veía claramente. Un ejemplo en este sentido es el de un obrero que falleció luego de levantar una plancha de hierro, caso en el cual se procedió a indemnizar a la familia. En cambio, un cocinero que al levantarse por la mañana sufrió un síncope cardíaco no fue indemnizado ya que nada indicaba, según el juez, la relación entre el oficio y la enfermedad profesional. Para otras dolencias, los fallos fueron contradictorios, a saber: las hernias, las muertes por insolación y la tuberculosis. Con respecto a esta última, se dio una situación muy particular: no estaba comprendida en el decreto reglamentario del Poder Ejecutivo Nacional, pero sí en la reglamentación de la provincia de Buenos Aires. La inclusión realizada por las autoridades bonaerenses fue objeto de arduas discusiones ya que, según algunos tratadistas, las autoridades provinciales no tendrían facultades para ampliar las disposiciones realizadas por una ley federal. Esta situación da cuenta de las diferencias en cuanto a la legislación vigente dentro de un sistema federal. Cada provincia, al contar con la autonomía legislativa y ejecutiva, podía resolver situaciones de distinta forma. En una misma provincia, los horarios de trabajo, los salarios o el resguardo a las condiciones laborales podían cambiar si la persona estaba regida por el sistema federal o provincial.

Las perspectivas que indicaban a la tuberculosis como una enfermedad pasible de ser indemnizada señalaban que los cambios de temperatura, las mojaduras, las cámaras frías y las condiciones antihigiénicas y precarias tendían al agravamiento de esta enfermedad o a una mayor predisposición a contraerla. A la sazón, la Cámara Civil Primera de Apelaciones ratificó que si el "el proceso bacilar originado por las tareas que desempeña el obrero se agudiza debería considerarse un accidente de trabajo y como consecuencia debería ser indemnizado". 28

En cuanto a las posiciones en relación con las enfermedades cardíacas, éstas fueron cambiando dentro de las discusiones en torno a las dolencias producidas a causa del trabajo. Si bien existieron fallos que negaron la relación de causalidad entre trabajo y enfermedades del corazón, hacia los años cuarenta, el médico Guillermo Bosco, profesor titular de la Facultad de Buenos Aires y médico del Hospital Ramos Mejía, enfatizaba la importancia de que las enfermedades del corazón fueran incluidas dentro de la tutela pública y la de las entidades privadas, debido a la invalidez que ocasionaban y la consecuente inhabilitación para

28 "Jurisprudencia del Trabajo". Boletín informativo de Leyes de Trabajo, marzo de 1942, p. 59. 
llevar a cabo las tareas. ${ }^{29}$ Estas ideas habían sido reforzadas por la Cámara Comercial de la Capital, la cual, ante la duda de relación entre trabajo y síncope cardíaco, señalaba que este daño debía indemnizarse como accidente de trabajo. Situación similar acontecía con el paludismo, que si bien no aparecía ente las dolencias especificadas, según la Sala II de la Cámara de Paz Letrada, si un obrero contraía esta enfermedad mientras trabajaba, constituía un accidente de trabajo indemnizable. ${ }^{30}$

Para determinar las compensaciones se tuvieron varios referentes legislativos. Alemania poseía un sistema corporativo patronal controlado por el Estado. En Austria también existía un sistema corporativo, pero los obreros contribuían a financiarlo. En Bélgica, existía un seguro obligatorio por parte del patrón. En la Argentina se instauró un sistema de responsabilidad individual, no corporativa, de acuerdo con el cual los patrones podían traspasar a las compañías de seguro las cargas de las indemnizaciones. Esta situación dio lugar a que las grandes empresas contrataran aseguradoras privadas, muchas de ellas de origen extranjero, tales como Compaignes D'Assurances Générales, La Franco Argentina, Libertad, La Reserva, La Economía Comercial.

En la Crónica Mensual del Departamento Nacional del Trabajo se denunciaba a las compañías de seguros que no cumplían con las obligaciones para con los trabajadores accidentados. Entre las artimañas habituales para eludir las obligaciones de la indemnización se encontraba la búsqueda de errores ortográficos en los apellidos, la falta de registro por parte del patrón de los libros de sueldos y jornales, la inexistencia de la firma del patrón en la denuncia del accidente, la existencia de arreglos extrajudiciales de las compañías aseguradoras y el intento de demostrar que la víctima tenía la culpa por el accidente, motivada por su imprudencia o por una lesión previa. La suma de situaciones turbias podía dar lugar a que el Poder Ejecutivo retirara a las compañías de seguro la autorización para operar en el rubro de accidentes de trabajo. Este fue el caso de las compañías de seguros La Central (1926) y El Mundo (1927), La Unión Médica Argentina (1930) y La Comercial e Industrial de Avellaneda (1930). La Central contó con varias denuncias en relación con la falta de pago de indemnizaciones. ${ }^{31}$ El Mundo fue denunciada por eludir y dilatar los pagos; en palabras textuales, por "cobrar mucho y pagar poco". ${ }^{32}$ Las cartas de los funcionarios dirigidas al ministro del Interior pidiendo la desautorización de las compañías de seguros y los dictámenes del procurador del Tesoro avalando tal decisión eran publicadas en las Crónicas Mensuales. Este material se convirtió en una suerte de mensaje ejemplificador en la medida que daba cuenta de que las denuncias eran relevadas por la agencia estatal y que luego el

\footnotetext{
${ }^{29}$ BOSCO, Guillermo. "Algunas consideraciones sobre enfermedades del corazón y del trabajo". Boletín Informativo de Leyes de Trabajo, junio de 1942, pp. 47-49.

30 "Jurisprudencia del Trabajo". Boletín linformativo de Leyes de Trabajo, septiembre de 1942, p. 59.

31 "Nota elevada por el Departamento Nacional del Trabajo al Ministerio del Interior, relacionada con la compañía de seguros La Central”, 30 de noviembre de 1926. Crónica Mensual del Departamento Nacional del Trabajo, noviembre y diciembre de 1926, p. 1945.

32 "Decreto retirando la autorización acordada a la compañía de seguros El Mundo para operar en el ramo de accidentes de trabajo". Crónica Mensual del Departamento Nacional del Trabajo, año X, diciembre de 1927, N ㅇ 118, p. 2229.
} 
organismo aplicaba una sanción. ${ }^{33}$ Asimismo, la intervención de las múltiples empresas aseguradoras complejizaba aún más el escenario de las denuncias y el resarcimiento por lesiones laborales, puesto que se convertían en un actor más, dado que su objetivo era conseguir asegurados pero intentar no pagar nada o pagar por las lesiones la menor cantidad de dinero posible.

¿Cómo funcionaba el financiamiento? Por medio del sistema de renta: los patrones o las compañías aseguradoras depositaban la indemnización en una sección especial: la Caja Nacional de Jubilaciones y Pensiones Civiles. Es por tal motivo que la agencia estatal denunciaba las irregularidades patronales o de las compañías aseguradoras. ${ }^{34} \mathrm{Si}$ éstas no cumplían con la norma, le restaban recursos a la Caja. Esta institución las invertía en títulos de la Nación y pagaba mensualmente a las personas beneficiarias. Por medio de este sistema mensual se pretendía proteger a los indemnizados/as, ya que se creía que si se entregaba todo el dinero a las personas lesionadas o a sus deudos, estos no podrían administrarlo correctamente y luego caerían en la indigencia, con lo cual se convertirían en una "carga para la sociedad y el Estado". Es decir, la supuesta irracionalidad en el uso del dinero y del derecho era un medio para resguardar los recursos de la Caja Nacional de Jubilaciones y Pensiones Civiles.

Este sistema fue objeto de críticas, puesto que los pagos realizados mensualmente por la Caja resultaban insuficientes para vivir. Es por este último motivo que el 25 de julio de 1918, a iniciativa del doctor Alejandro Unsain, se dictó otro decreto reglamentario por el cual la indemnización se recibiría en 120 mensualidades, es decir, durante diez años.

Debido a las limitaciones impuestas por el Código Civil, existían diferencias entre varones y mujeres en cuanto al pago de la indemnización. Cuando los titulares de las rentas eran hijos, nietos, hermanos (varones) de la víctima, recibirían el dinero por medio de sus representantes legales hasta que cumplieran la mayoría de edad. En ese momento, sería liquidado el resto del dinero que aún no había sido abonado. En el caso de hijas, nietas y hermanas, la indemnización podría ser reclamada cuando contrajeran matrimonio. Esta situación se modificó a instancias de la sanción de los derechos civiles de las mujeres, en 1926. A partir de entonces, las mujeres mayores de edad que no estuvieran casadas, y las viudas (por lo general, eran las esposas de los difuntos quienes iniciaban la tramitación administrativa y judicial) pudieron gozar de sus derechos civiles. ${ }^{35}$

En los casos de lesiones parciales o temporales, las liquidaciones se harían directamente a los lesionados en un único pago. Este decreto fue modificado el 25 de octubre de 1925. En esta modificación se estableció que los jueces serían los únicos intérpretes de la ley y también quienes determinasen cómo entregar la indemnización. No obstante, el 27 de julio de 1928 se retomó la propuesta de Unsain, que se hacía eco de los principios de la VII

\footnotetext{
33 "Aplicaciones de las leyes obreras en vigor". Crónica Mensual del Departamento Nacional del Trabajo, junio de 1928, Imprenta y Papelería Denuble, Buenos Aires, Año XI, N 124, p. 2386.

${ }^{34}$ Entre 1916 a 1930 se habían autorizado 35 compañías aseguradoras. Véase Crónica Mensual del Departamento Nacional del Trabajo, año XIII, № 146, abril de 1930, p. 3133.

35 BARANCOS, Dora. Mujeres en la sociedad argentina. Una historia de cinco siglos, Buenos Aires, Sudamericana, 2007.
} 
Conferencia Internacional del Trabajo reunida en Ginebra (1925). La provincia de Buenos Aires mantuvo la decisión de darle la autoridad al juez para determinar la situación más conveniente.

Dentro de las "incapacidades parciales", la pérdida de brazos y manos eran las que recibían una indemnización de hasta el $60 \%$ del salario, la pérdida de dedos era variable entre un $6 \%$ (falange del dedo anular o del pie) a un $24 \%$ (índice derecho). Por la pérdida de una pierna se pagaba un $60 \%$; por ceguera y sordera, un $42 \%$; por hernia, entre un $18 \%$ a un $12 \%$. El cuerpo tenía un valor adjudicado por criterios subjetivos que no siempre estaban en sintonía con las efectivas prácticas de las personas. De hecho, la parte derecha del cuerpo tenía un valor mayor que la izquierda, lo que ponía en tensión aquellas acciones realizadas por las personas que utilizaban, por ejemplo, su mano izquierda. Los zurdos cobrarían, si no apelaban ante la Justicia, menos dinero que las personas diestras.

En algunos fallos, se tuvieron en cuenta la naturaleza del trabajo y la determinación de elementos subjetivos tales como profesión y edad. ${ }^{36}$ Éste podría haber sido el caso de Rinaldo Racsta, obrero de la Compañía Argentina de Navegación Mihanovich Limitada en San Fernando, en 1941. Rinaldo tenía 56 años de edad y veinte años de dedicación a una actividad de especialización (no declarada). Estos dos elementos, la especialización y la edad, influyeron para determinar que la pérdida de la visión de ambos ojos representaba una incapacidad permanente y, por lo tanto, debía ser indemnizado. ${ }^{37}$

Otro caso constituye el relatado por el profesor de Medicina Legal de Córdoba Ariosto Licurzi, quien, avalado por su intervención en más de siete mil casos de accidentes, enunció lo arbitrario del nomenclador de indemnizaciones, al cual llamaba la "tarifa de carnicería". Tomó como ejemplo el accidente de un obrero de la construcción que había perdido el dedo mayor del pie y fue indemnizado con el $6 \%$ de su salario. Según el médico cordobés, ese resarcimiento no contemplaba que su capacidad para el trabajo había disminuido sensiblemente; para este tipo de oficios, el equilibrio era fundamental, y esta lesión impediría a este obrero, a futuro, subirse a un andamio debido a la pérdida de estabilidad que suponía. En estos casos, proponía la reeducación y readaptación de los lesionados para que pudieran realizar otras tareas. La justificación de este argumento tenía un correlato en el temor que en su opinión generaba el hecho de que estas personas, al perder el trabajo y sus posibilidades de reinserción, cayeran en la pobreza, que - con una interpretación sin matices- sería un tobogán para la delincuencia. A la sazón, en este argumento médico, el impulso a las reformas sociales venía legitimado por el temor al conflicto social y a la delincuencia. ${ }^{38}$

La sanción, implementación y diferentes modificaciones que se le hicieron a la Ley de Accidentes de Trabajo significó el reconocimiento por parte del Estado de las pésimas condiciones laborales que venían denunciando desde fines del siglo XIX diferentes agrupaciones políticas y sindicales. La prescripción jurídica motorizó el surgimiento de un

\footnotetext{
${ }^{36}$ RIVA, Oscar Alfredo. "Diversas teorías sobre la reparación de accidentes". Boletín Informativo de Leyes de Trabajo, marzo de 1942, p. 47.

37 "Otro fallo sobre accidentes de trabajo". Boletín Informativo de Leyes de Trabajo, septiembre de 1943, pp. 33-34.

${ }^{38}$ LICURZI, Ariosto, "Faltas de sentido médico en la legislación social argentina". La Prensa Médica Argentina, № 1, 1938, p. 35.
} 
andamiaje institucional - tanto dentro del ámbito público como en el privado- que, a medida que fue creciendo, generó disputas sobre quiénes tenían mayores atribuciones y recursos para intervenir en dichas relaciones laborales. Este escenario se complejizaría a mediados del siglo $\mathrm{XX}$ con las ideas que impulsaban la necesidad de crear sistemas de seguridad social constituidos sobre principios de ciudadanía y no sólo por la relación salarial. A continuación, revisaremos cómo estas discusiones, que atravesaron al mundo occidental de la segunda posguerra, se amalgamaron con el proceso político local del peronismo.

\section{DEL RIESGO AL SEGURO}

Durante la segunda posguerra, las propuestas en torno a la organización de los sistemas de seguridad social atravesaron la arena pública nacional e internacional. Esto es, la protección de las personas debería regirse por principios de la solidaridad social y no por la intervención de las empresas aseguradoras. Los referentes internacionales mencionados tanto en los espacios de difusión profesional como en el diseño normativo fueron el Informe de William Beveridge de Gran Bretaña (1941), el Plan Marsh de Canadá y los planes WagnerMurray-Dingell de la Junta de Seguridad Social y la Junta de Planificación de Estados Unidos (1945), y la Ley del Servicio de Sanidad Pública de Inglaterra (1946). Del conjunto de América Latina, las experiencias de Chile y Perú tenían un espacio en las referencias discursivas. Chile, por ser considerado un país pionero en la sanción de las leyes que tendieron a proteger a los trabajadores en momentos de invalidez y enfermedad, y Perú por haberse constituido allí -en 1936- el seguro social obrero, cuya concreción más destacada fue la inauguración, en 1940, del Hospital Obrero de Lima.

Dentro de estos debates, tanto en la creada Secretaría de Trabajo y Previsión (1944) como en la Secretaría de Salud Pública (1946), las discusiones políticas y técnicas giraron en torno a la constitución del "Seguro Social". El ideal apuntaba a universalizar la asistencia sanitaria y social entre la población obrera; es decir, no sólo a entregar una prestación económica por la lesión, sino a mejorar y ampliar la asistencia médica y social y estimular estrategias de reeducación a las personas lesionadas.

En la pretendida universalidad de las prestaciones sociales se tendió a dar prioridad a aspectos "importantes" que redundaran en contra de la capacidad de trabajo (enfermedades profesionales, tuberculosis, dolencias cardiovasculares, lues, reumatismo, 
lepra, tracoma, paludismo, anquilostomiasis) y, en una segunda etapa, se abocarían a "otros temas" (el Seguro de Accidentes de Trabajo y el Seguro Maternal). ${ }^{39}$

Entonces, cabe preguntarse ¿qué cambios introdujo el peronismo? En materia institucional, en 1944, con el fin de dar los primeros pasos para la constitución del ansiado proyecto de "Seguro Social", se creó por decreto el Instituto Nacional de Previsión Social (INPS) bajo la dependencia de la Secretaría de Trabajo y Previsión, y se dictó el Decreto Ley de Medicina Preventiva y Curativa (Ley № 30.656). El INPS incorporó a las distintas cajas, entre las cuales estaban la Caja de Maternidad y la de Pensiones. Ambas perdieron su autarquía administrativa, pero conservaron sus fondos. El INPS estaba destinado a realizar la unificación administrativa, la mejor distribución y la aplicación de las prestaciones, la sistematización de los procedimientos y el estudio financiero de los regímenes de previsión social. Se proponía culminar en la consolidación de un sistema centralizado y uniforme, que superara la variedad de situaciones existentes, homogeneizara los requisitos para acceder a los beneficios, extendiera la cobertura a la población no incluida y agilizara la tramitación.

EI INPS, bajo la tutela de la Secretaría de Trabajo y Previsión, aportaría los fondos necesarios para que la Secretaría de Salud Pública garantizara la asistencia médica preventiva y curativa de las personas afiliadas. Así pues, por medio del seguro social se pretendía controlar ciertos padecimientos que repercutían en la "capacidad física y técnica del trabajador", esto es: la tuberculosis, las afecciones cardiovasculares, la sífilis, el reumatismo, las dolencias profesionales, el bocio, el paludismo, la anquilostomiasis y la detección de enfermedades que podrían causar severos problemas clínicos a futuro (caries dentales, focos sépticos, infecciones gástricas, alteraciones gástricas, obesidad, diabetes). En dicha enunciación restrictiva, la maternidad quedaba en un limbo legal. En este sentido, son claras las afirmaciones de Germinal Rodríguez, personaje clave en la gestión sanitaria entre 1946 a 1949, ya que fue quien organizó los Archivos de la Secretaría de Salud Pública y ocupó el cargo de Director de Medicina Preventiva en la Secretaría de Salud Pública, ${ }^{40}$ quien hizo un balance de la Ley de Medicina Preventiva en 1949, cuando sostuvo

la ley es enumerativa y restrictiva desde que no tan sólo enumera las enfermedades hacia las cuales se dirige, sino también que limita la atención [...] y de ninguna manera ha sido la intención de la ley en la pluma de sus creadores, la de convertirla en una ley de asistencia general sin límites, que llegue a dispensar la

\footnotetext{
${ }^{39}$ RODRÍGUEZ, Germinal. "Planificación de los Servicios de Medicina Preventiva”. Clínica del Trabajo, Año VI, № 19 a 21, enero, febrero, marzo, 1946. Estas prioridades también se establecen en CARRILLO, Ramón. "Nuevas Conquistas Sociales" (Discurso que pronunció Carrillo al dejar constituida la Comisión Mixta encargada de aplicar la ley de medicina preventiva). Clínica del Trabajo, Año VI, № 22 a 24, julio a septiembre de 1946, pp. 710.

${ }^{40}$ Véase datos biográficos e importancia de Germinal Rodríguez en RAMACCIOTTI, Karina. La política sanitaria del peronismo, Biblos, Buenos Aires, 2009.
} 
atención médica de un enfermo imposible de recuperación. Estos casos de orden humanitario les corresponde su asistencia a otros organismos. ${ }^{41}$

No obstante este intento de unificación de las Cajas, este proyecto quedó trunco con la Ley № 14.236 de 1953. El INPS perdió definitivamente sus atribuciones y quedó subsumido a la Dirección General de Previsión Social, dependiente del Ministerio de Trabajo y Previsión; aunque las cajas recuperaron su individualidad orgánica y funcional, personería jurídica y autarquía administrativa y financiera. La Caja de Maternidad y la de Accidentes de Trabajo pasaron a depender del Ministerio de Trabajo y Previsión, y el Ministerio de Salud perdió, de este modo, toda injerencia en el terreno de la salud laboral.

Esto fue visto como un vaciamiento de atribuciones ya que, en sus inicios, el Departamento Nacional de Higiene (1880) -creado en forma previa al Departamento Nacional del Trabajo (1907)- tenía el monopolio de los conocimientos en torno a la salud de los y las trabajadores/as y desde su agencia surgieron los primeros informes y publicaciones sobre la higiene en los ámbitos de trabajo. En 1949, la sanción de la Ley Orgánica de los Ministerios (Ley № 13.529) tuvo en cuenta la división de tareas entre las reparticiones laborales y sanitarias. En ella se determinó que el Ministerio de Salud tendría la función de dirigir las actividades vinculadas a la medicina preventiva, higiene y medicina de trabajo y las prestaciones por los riesgos; mientras que el Ministerio de Trabajo y Previsión supervisaría lo inherente a la policía sanitaria. ${ }^{42}$

Este reajuste de funciones se sumaba al que ya se había producido en 1948. Entre 1946 y 1948, las inspecciones sanitarias en los ambientes laborales eran una atribución de la agencia sanitaria. Si se confirmaba la existencia de tareas insalubres se podía determinar la reducción de la jornada laboral (seis horas de trabajo en lugar de ocho) sin reducción del salario. Desde 1948, estas funciones pasaron a la agencia laboral. La Secretaría de Salud Pública quedó abocada a resolver cuestiones técnicas, científicas y de divulgación.

La poda de recursos y la imposibilidad de centralizar llevaron al Secretario de Salud a denunciar lo que era visualizado como una pérdida de espacios políticos:

Quiero dedicar un recuerdo al viejo Departamento Nacional de Higiene, donde se inició la Medicina del Trabajo en la Argentina y donde debe seguir, de acuerdo a nuestra tradición y a las leyes de la Nación, porque la nueva ciencia, si ha sido creada y fundada por médicos, debe seguir en manos de médicos, que son los únicos que, por órgano nacional de la sanidad, están en condiciones de resolver

\footnotetext{
${ }^{41}$ Medicina del Trabajo y Medicina Preventiva. Archivos de la Secretaría de Salud Pública, vol. V, № 2, febrero 1949, pp. 23-129. El destacado es nuestro.

${ }^{42}$ TISSEMBAUM, Mariano. "Reformas a la ley Argentina de Accidentes de Trabajo". En Primer Congreso Americano de Medicina del Trabajo, Buenos Aires, 1 al 14 de diciembre de 1949. Conclusiones y Trabajos, pp. 180-186.
}

Revista Mundos do Trabalho, vol. 3, n. 5. 
con imparcialidad y espíritu científico los múltiples problemas de la industria en su relación con la patología del trabajo. ${ }^{43}$

El lamento y malestar por un supuesto pasado institucional lejano e idealmente mejor entraba en tensión con el andamiaje institucional creado a partir de 1946, cuyo lanzamiento también fue postulado como el quiebre de una época "oscura" que daría inicio a un futuro "luminoso".

\section{A MODO DE CONCLUSIÓN}

En este artículo se demostró que, en materia de salud laboral, el Estado tuvo injerencias desde las primeras décadas del siglo XX. En las instancias administrativas que intervinieron en esta temática se vieron involucradas las dependencias laborales, las sanitarias y las judiciales.

El corpus, compuesto por revistas médicas y publicaciones del Departamento Nacional del Trabajo, permite observar que, frente a las demandas realizadas por las víctimas, la jurisprudencia -avalada por los informes de los médicos y abogados- sentó precedentes que fueron retomados por los cambios introducidos por los decretos reglamentarios posteriores. En esta línea, consideramos que para estudiar las políticas sociales es necesario revisar las reivindicaciones obreras y cómo éstas colaboraron a crear una agenda de temas prioritarios, así como también investigar los cruces y diálogos entre las diferentes reparticiones del Estado cuando se formula una prescripción normativa. Probablemente, a partir del estudio de una ley y sus modificaciones durante un período determinado sea más factible analizar las porosidades, conflictos y superposiciones entre las agencias de gobierno; además de revisar cómo los saberes profesionales van ocupando un rol cada vez más relevante para la construcción de la política estatal. Esta mirada, a futuro, debería complementarse con el accionar de las reivindicaciones del movimiento obrero y con el análisis de cómo el diálogo y el conflicto entre los obreros, el Estado, la patronal y las compañías aseguradoras permitieron que se comenzaran a reconocer un mínimo de derechos laborales y cómo en este proceso se comenzó a concebir a los obreros como ciudadanos de pleno derecho en la comunidad nacional.

Junto con la jurisprudencia, las voces profesionales tendieron a una mayor especialización en sus saberes, lo cual quedó demostrado en la profusa cantidad de publicaciones periódicas y libros que tuvieron como eje principal la medicina del trabajo. Los temas de interés pendularon entre la responsabilidad individual y la responsabilidad social.

\footnotetext{
${ }^{43}$ CARRILLO, Ramón. "Discurso pronunciado por el Señor Secretario de Salud de la Nación, profesor Ramón Carrillo". En Primer Congreso Argentino de Medicina del Trabajo, Vol. 1, Buenos Aires, Libreros López \& Etchegoyen, 1948.
} 
Esta cuestión, a tono con el clima de la segunda posguerra, ocupará el centro del debate en los inicios del peronismo y el intento frustado de implementar el seguro de salud.

Reflexionar sobre los cambios y las permanencias de un mismo corpus legislativo por casi cincuenta años nos permite aventurar algunas hipótesis. Durante fines de los años veinte y los cuarenta se abulta la producción y las discusiones en torno a cómo proteger la salud laboral de los trabajadores. En esta línea, los saberes se irán especializando, y cada vez más enfermedades -que en décadas anteriores habían permanecido en una suerte de limbo legal- comenzaron a ser consideradas jurídicamente como enfermedades vinculadas a la jornada laboral. Por último, podemos anticipar que el ministerio de Trabajo, durante los años peronistas, fue ganando predominancia por sobre la cartera de Salud respecto de estas cuestiones $y$, en forma paralela, la aspiración de lograr el seguro de salud quedó en proyectos y discusiones que no lograron incidir en el proceso político.

Recebido em 21/10/2010

Aceito para publicação em 31/03/2011 